and traumatic life events on mental and physical health are well established. For instance, Bhui et al (2006) found higher rates of mental disorders among refugees who experienced life-threatening traumatic events than among those who did not experience such events. Similarly, Steel et al (2002) found that exposure to events in one or more trauma categories resulted in a twofold increase in risk of mental illness, but exposure to events in three or more trauma categories led to a four- to sixfold increase, compared with those exposed to no traumatic events.

The Pan Arab Conference of Psychiatry in 2008, held in Damascus, Syria, where most of the Iraqi refugees are, highlighted the plight of Iraqis with mental health needs (Essali, 2008). For example, one presentation of data from the UNICEF clinic in Damascus suggested that almost $11 \%$ of the refugee Iraqi children presented to this clinic with symptoms of post-traumatic stress disorder (Jahshan, 2008). Although there was no actual survey of the psychiatric problems of the Iraqi refugees, the meeting of the Arab Federation of Psychiatrists suggested that the main theme of the next Pan Arab Conference should be the mental health needs of Iraqis and Iraqi refugees. This is a reflection of the level of concern over the mental health needs of this group. The mental health and social care professionals working in the regions where there is a large presence of Iraqi refugees have been calling for improved mental health services for both displaced Iraqis and refugees, but there has been little international response to date (Essali, 2008).

There is a clear necessity for a comprehensive study to assess the mental health needs of Iraqi refugees. We need to know the scale of the problem. Data on gender and group vulnerabilities to psychological problems among Iraqis are limited. Much more information is urgently required to establish mental health services for these groups. The international community has a duty to address the mental health needs of traumatised Iraqis in order to reduce the kind of disability and impairment problems associated with war and conflict. There are also many Iraqi doctors and mental health professionals, who must be encouraged and mobilised to deliver culturally sensitive mental health services.

W. K. Abdul-Hamid ${ }^{1}$ and Nasir Warfa ${ }^{2}$

${ }^{1}$ Consultant Psychiatrist and Honorary Senior Lecturer; 'Lecturer and MSC Coordinator, Centre for Psychiatry Queen Mary University of London, Barts \& The London School of Medicine and Dentistry, Wolfson Institute of Preventive Medicine, Charterhouse Square, London EC1M 6BQ, UK

Bhui, K., Craige, T., Mohamud, S., et al (2006) Mental disorders among Somali refugees. Social Psychiatry and Psychiatric Epidemiology, 20, 1-9.

Essali, A. (2008) XIth Pan Arab Conference of Psychiatry. Psychological consequences of violence and evidence-based mental health. Arabpsynet Journal, 18, 1-7.

Jahshan, S. (2008) Referral system at the UNICEF and Red Crescent clinics. XIth Pan Arab Conference of Psychiatry, 21 August.

Steel, Z., Silove, D., Phan, T., et al (2002) Long-term effect of psychological trauma on the mental health of Vietnamese refugees resettled in Australia: a population-based study. Lancet, 360, 1056.

\section{Kerala fundraising trek, 2009}

C: In January 2009 I was one of 14 who went to - Kerala on a 5-day trek to raise money for the College Volunteers Programme. We were 11 psychiatrists and three non-psychiatrists (who happened to be carers of family members with mental health problems). We started from coastal Kerala and climbed close to 9000 feet over the mighty mountains of Munnar into Tamil Nadu, covering almost $130 \mathrm{~km}$. The walk was tough but the scenery was breathtaking. We had the opportunity to visit a village school in the mountains and make a contribution to their education. We also visited the Trivandrum Mental Health Centre, which gave us the opportunity to see what mental health services look like in India. We were impressed by what we saw and witnessed some examples of good practice, such as accommodation facilities for visiting relatives. We were also able to appreciate the challenges they faced in terms of funding and stigma. For many, this was the first time they saw what services in a low-income country looked like. We also were able to meet some patients. Part of the group went on to conduct a workshop in Sri Lanka, which was well received.

We stayed in tents for the entire duration of the trek and were looked after very well by our organisers and guides. The food was excellent. A few of us knew each other before the trek but many first met on the trip. Very soon, however, we got on really well and now feel as if we share a close bond with each other. It worked like the ultimate team-building exercise and we feel committed as a group to volunteer work in mental health and are already talking about the next trek. Some have suggested that it should be in the Shillong region in India, where I have started a volunteer project.

The trek was part of the College President's appeal when Professor Sheila Hollins was leaving office in 2008. She successfully completed the trek herself and handled many of its organisational aspects when in India. The trek raised an impressive sum - over $£ 30000$ - for the Volunteers Programme. This will be used for bursaries for volunteers to visit to low- and middle-income countries. The Programme currently supports placements in Africa, Iraq and other parts of the world but has until now lacked funds. I was amazed by how successful the trek was and think that it is an excellent way not only to raise funds but also to raise the profile of the Programme. It brought together some committed people who can be called upon again in the future.

The trekkers were: Chris Dobson, Sally Pidd, Carol Henshaw, Elspeth Bradley, Adrienne Regan, Brian Martindale, Carola Mathers, Dale Mathers, Adil Akram, Sheila Hollins, Martin Hollins, Karen Stevens, Sally Browning and Allen Kharbteng.

Allen Kharbteng email allenkharbteng@hotmail.com

Correspondence is welcome either on articles published in International Psychiatry or on aspects of current policy and practice in psychiatry in different countries. Letters (of up to 500 words) should be sent to:

Amit Malik MRCPsych, Consultant Psychiatrist, Hampshire Partnership NHS Trust, UK email ip@rcpsych.ac.uk. 